\title{
Advances in the treatment of type 2 diabetes: impact of dulaglutide
}

This article was published in the following Dove Press journal:

Diabetes, Metabolic Syndrome and Obesity: Targets and Therapy

4 May 2016

Number of times this article has been viewed

\section{Angela M Thompson \\ Jennifer M Trujillo}

Department of Clinical Pharmacy, University of Colorado Skaggs School of Pharmacy and Pharmaceutical Sciences, Aurora, CO, USA
Correspondence: Angela M Thompson University of Colorado Skaggs School of Pharmacy and Pharmaceutical Sciences, I 2850 East Montview Boulevard - mail stop C238, V20-1215, Aurora, CO 80045, USA

Tel +I 3037248756

Email angela.thompson@ucdenver.edu
Abstract: The purpose of this review is to provide a review of current data of the most recently approved glucagon-like peptide (GLP)-1-receptor agonist, dulaglutide, in the treatment of type 2 diabetes. To complete this, a PubMed search was performed to identify manuscripts published from 1947 to July 2015. The search terms “Trulicity”, “dulaglutide”, and "LY2189265" were utilized, and publications were included if they evaluated the pharmacology, pharmacokinetics, efficacy, safety, or patient-reported outcomes of dulaglutide. Dulaglutide is a GLP-1 receptor agonist that mimics endogenous GLP-1, the hormone produced in response to food intake. Modifications have been made to the molecule to delay breakdown and allow for once-weekly dosing. Dulaglutide has been studied as monotherapy and in combination with several agents, including metformin, glimepiride, pioglitazone, and insulin lispro. Dulaglutide has demonstrated superior efficacy compared to placebo, metformin, insulin glargine, sitagliptin, and twice-daily exenatide. It was found to be noninferior to liraglutide. The most common adverse effects in clinical studies were gastrointestinal-related adverse events, and patient satisfaction was high with the use of dulaglutide. Dulaglutide is an appealing option for the treatment of type 2 diabetes, based on its once-weekly dosing, A1c lowering comparable to liraglutide, weight reduction comparable to exenatide, and a similar adverse-effect profile to other GLP-1 receptor agonists.

Keywords: dulaglutide, GLP-1 receptor agonist, T2D

\section{Introduction}

Diabetes continues to be a national and global epidemic. Approximately 387 million people worldwide have diabetes, and this number is expected to increase to 592 million people by $2035 .^{1}$ The prevalence of diabetes in the US has also been steadily rising. Currently, 29.1 million Americans have diabetes, and at the current pace, one in three American adults will have diabetes in their lifetime. ${ }^{2}$

Type 2 diabetes (T2D) is a progressive disease characterized by insulin resistance and progressive $\beta$-cell dysfunction, leading to worsening glycemic control over time, which can ultimately lead to micro- or macrovascular complications. ${ }^{3}$ Diabetes continues to be a leading cause of death in the US, and contributes significantly to cardiovascular disease, kidney disease, retinopathy, blindness, peripheral neuropathy, and amputations. ${ }^{2}$ The costs associated with diabetes and its complications are staggering. Total costs were estimated at $\$ 245$ billion in the US in $2012 .^{2}$ The progressive nature of the disease, growing prevalence, substantial risk for complications, and escalating costs provide clear necessity for effective, safe, and durable treatment options for glycemic control. 


\section{Current and emerging treatments for managing type $\mathbf{2}$ diabetes}

Lifestyle modifications, including weight loss, dietary changes, and increased physical activity, remain crucial to achieving and sustaining glycemic control and reducing the risk of long-term complications. However, the vast majority of patients with T2D require medications in addition to lifestyle modifications to achieve sustained glycemic control. ${ }^{2}$

Significant therapeutic advances have been made in the pharmacological management of hyperglycemia in patients with T2D. For many years, the treatment of T2D was limited to sulfonylureas, metformin, and thiazolidinediones. Insulin was commonly reserved for use in the late stages of the disease. Today, significantly more is known about the multiple pathophysiologic defects of T2D, and as many as 14 classes of T2D medications are available, making the treatment decisionmaking process increasingly complex. ${ }^{3,4}$ In many patients, effective glycemic control requires multiple drugs used in combination to correct multiple pathophysiologic defects. ${ }^{3}$

Current treatment recommendations by both the American Diabetes Association and the American Association of Clinical Endocrinologists promote a patient-centered approach that takes into consideration the efficacy of the drug as well as the pharmacological action, effect on weight, tolerability, and long-term safety. ${ }^{4-8}$ Both treatment-recommendation algorithms promote early lifestyle management and metformin, and quickly progress to combination therapy through individualized decision making.

Metformin remains the cornerstone of T2D therapy, providing good reductions in A1c, low incidence of hypoglycemia, and mild weight loss. The UKPDS study demonstrated that in overweight individuals, early, intensive glycemic control with metformin reduced the risk of any-diabetes related end point, myocardial infarction, and death from any cause, and this benefit persisted for 10 years of posttrial follow-up. ${ }^{9}$ Metformin is oral and inexpensive, which are also important advantages for this first-line option.

Sulfonylureas remain viable options for T2D and provide effective Alc-lowering effects. These agents are oral, taken once or twice daily, and are remarkably inexpensive. However, they do increase the risk of hypoglycemia and cause weight gain. While thiazolidinediones offer several advantages, including effective A1c lowering, oral once-daily administration, and low cost, the multitude of safety concerns have led to a decline in their use. Safety and tolerability concerns include weight gain, edema, reduced bone mineral density, increased risk of heart failure, fractures, and bladder cancer. ${ }^{10}$ Basal insulin offers several advantages, including the ability to titrate the dose to individual patient needs. Basal insulin can also be delivered via a pen device either once or twice daily. Although all insulin agents increase the risk of hypoglycemia and weight gain, the hypoglycemia risk is much lower with basal insulin compared to premixed or neutral protamine Hagedorn insulin. ${ }^{10}$

More recent additions to the T2D-treatment armamentarium include glucagon-like peptide-1-receptor agonists (GLP-1 RAs), Dipeptidyl peptidase-4 (DPP4) inhibitors, and sodium-glucose cotransporter (SGLT2) inhibitors. Unfortunately, despite the expansion of treatment options, achieving glycemic control targets remains elusive for many patients.

Recent evidence from the National Health and Nutrition Evaluation Survey shows that even with medication therapy, only about half of patients with diabetes achieve a target A1c $<7 \% .{ }^{11}$ Barriers to achieving glucose control include factors beyond drug efficacy, such as adherence, cost, fear of hypoglycemia, weight gain, and clinical inertia. Therefore, in addition to good A1c-lowering effects, there are several additional factors to consider for emerging therapies in T2D, including ease of administration, convenient dosing frequency, effect on weight, tolerability, risk of hypoglycemia, effects on cardiovascular outcomes, and long-term safety concerns.

Recent evidence from mandated cardiovascular safety studies has provided significant insight into the cardiovascular effects of certain novel agents. To date, these studies have demonstrated overall cardiovascular safety of the DPP4 inhibitors sitagliptin, ${ }^{12}$ saxagliptin, ${ }^{13}$ and alogliptin. ${ }^{14}$ Of note, saxagliptin led to an increased risk of hospitalization for heart failure. ${ }^{13}$ The ELIXA study demonstrated the cardiovascular safety of the GLP-1 RA lixisenatide. ${ }^{15}$ Studies examining the cardiovascular safety of other GLP-1 inhibitors are under way. Specifically, the REWIND study is looking at the safety of dulaglutide in over 9,000 patients with T2D. ${ }^{16}$ In addition, recent evidence suggests that certain novel agents, such as DPP4 inhibitors when compared to sulfonylureas ${ }^{17}$ and the SGLT-2 inhibitor empagliflozin when compared to placebo, ${ }^{18}$ reduce the risk of cardiovascular outcomes. Emerging evidence also suggests that many of the newer agents achieve similar reductions in A1c compared to older therapies, but with neutral effects on weight or weight loss and with low rates of hypoglycemia. Results from one study suggest that patients are more adherent to treatment regimens that result in weight loss compared to those that result in weight gain. ${ }^{19}$

Issues related to weight and safety may explain the recent decline in use of some of the older T2D treatments. An audit 
of ambulatory physician practices in the US showed declining use of sulfonylureas and thiazolidinediones and increasing use of DPP-4 inhibitors and GLP-1 RAs between 2005 and 2012. GLP-1 RAs, however, are still not being used frequently and accounted for only $4 \%$ of treatment visits in $2012 .{ }^{20}$ Their use may however gain momentum as we continue to learn more about their efficacy and long-term safety.

GLP-1 RAs have proven to be a major advancement in the treatment of T2D. Currently, there are five GLP-1 RAs approved for use in the US and six approved for use in the EU (Figure 1). As a class, these agents offer many advantages, including effective A1c lowering, weight loss, and low risk of hypoglycemia. Current research and guidelines support the use of GLP-1 RAs as a second-line option, in combination with metformin, sulfonylureas, thiazolidinediones, and/or in combination with basal insulin as an alternative to prandial insulin. ${ }^{6,7}$

There are, however, important within-class differences between the drugs. Head-to-head trials indicate differences in A1c lowering and rates of gastrointestinal (GI) adverse events. ${ }^{21}$ Administration requirements, dosing, and cost are also significantly different (Table 1). ${ }^{22-26}$ Considering the heterogeneity of the class, each agent should be evaluated independently when making patient-specific treatment decisions. The purpose of this review is to provide an analysis of current data of the most recently approved GLP-1 RA, dulaglutide.

\section{Pharmacology/mode of action}

Dulaglutide is a GLP-1 RA that mimics endogenous GLP1 , the hormone produced in response to food intake. GLP-1 stimulates the secretion of insulin when glucose levels are elevated, resulting in a low risk of hypoglycemia. In addition, GLP-1 inhibits glucagon secretion and slows gastric emptying. Due to the inhibition of appetite caused by GLP-1, it may promote weight loss. ${ }^{27}$ Endogenous GLP-1 is quickly inactivated by DPP4; however, dulaglutide and other GLP-1 RAs are engineered to resist degradation by DPP4..$^{28}$ Dulaglutide consists of two GLP-1 analogues with identical amino acid sequences. These two amino acid sequences are 90\% identical to endogenous GLP-1, with modifications made to resist inactivation. ${ }^{22}$ These GLP-1 analogues have also

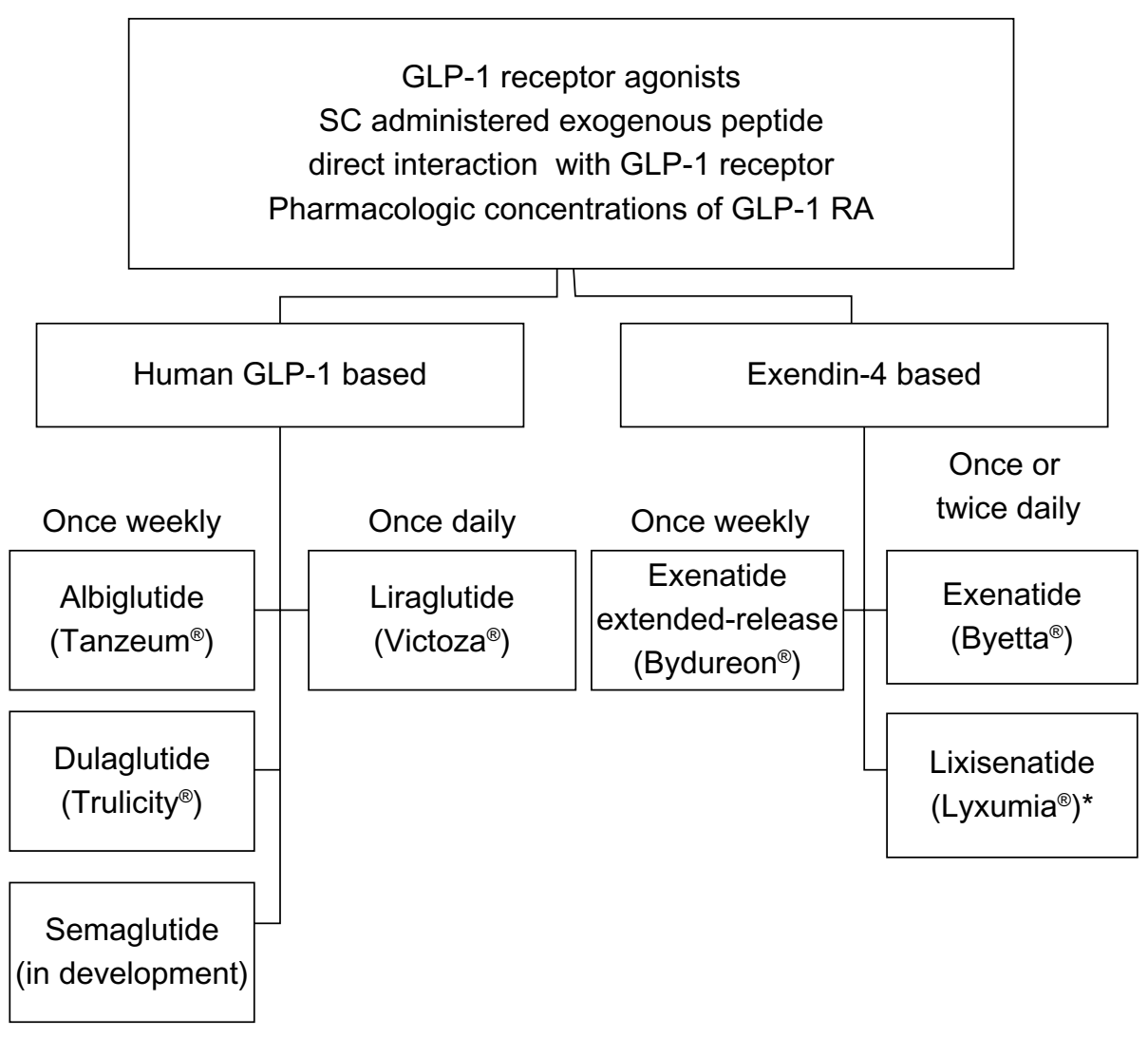

Figure I GLP-I-receptor agonists currently approved and in development.

Notes: *Not available in the US. Reproduced from Trujillo JM, Nuffer W. GLP-I receptor agonists for type 2 diabetes mellitus: recent developments and emerging agents. Pharmacotherapy. 2014;34(II):II74-I 186. ${ }^{21}$ With permission of John Wiley and Sons. Copyright (C) 2014.

Abbreviations: GLP, glucagon-like peptide; SC, subcutaneously; RA, receptor agonist. 
Table I Comparison of GLP-I-receptor agonists

\begin{tabular}{|c|c|c|c|c|c|c|c|}
\hline Drug & $\begin{array}{l}\text { Date of } \\
\text { FDA } \\
\text { approval }\end{array}$ & Dose & $\begin{array}{l}\text { SC } \\
\text { administration }\end{array}$ & $\begin{array}{l}\text { Delivery } \\
\text { device }\end{array}$ & Storage & $\begin{array}{l}\text { Renal function } \\
\text { considerations }\end{array}$ & $\begin{array}{l}\text { Cost (30-day } \\
\text { AWP), } \\
\text { US } \$ * 50\end{array}$ \\
\hline $\begin{array}{l}\text { Exenatide } \\
\left(\text { Byetta }^{\circledR}\right)\end{array}$ & April 2005 & $\begin{array}{l}5 \mu \mathrm{g} \times \mathrm{I} \text { month; } \\
\text { then I0 } \mathrm{gg} \text { if } \\
\text { tolerated }\end{array}$ & $\begin{array}{l}\text { Twice daily, } \\
30-60 \text { minutes } \\
\text { before meal }\end{array}$ & $\begin{array}{l}\text { Multiuse pen } \\
(5 \mu g, 10 \mu g)\end{array}$ & $\begin{array}{l}\text { Active pen - room } \\
\text { temperature; } \\
\text { refrigerate others }\end{array}$ & $\begin{array}{l}\mathrm{CrCl} 30-50 \mathrm{~mL} / \\
\text { min: use caution } \\
\mathrm{CrCl}<30 \mathrm{~mL} / \mathrm{min}: \\
\text { not recommended }\end{array}$ & $\$ 619.93$ \\
\hline $\begin{array}{l}\text { Liraglutide } \\
\left(\text { Victoza }^{\circledR}\right)\end{array}$ & $\begin{array}{l}\text { January } \\
2010\end{array}$ & $\begin{array}{l}0.6 \mathrm{mg} \times \mathrm{I} \text { week, } \\
\mathrm{I} .2 \mathrm{mg} \times \mathrm{I} \text { week, } \\
\text { then } 1.8 \mathrm{mg} \text { if } \\
\text { tolerated }\end{array}$ & Once daily & $\begin{array}{l}\text { Multiuse pen } \\
\text { (three doses in } \\
\text { one pen) }\end{array}$ & $\begin{array}{l}\text { Active pen - room } \\
\text { temperature; } \\
\text { refrigerate others }\end{array}$ & None & $\$ 769.18$ \\
\hline $\begin{array}{l}\text { Exenatide XR } \\
\left(\text { Bydureon }^{\circledR}\right)\end{array}$ & $\begin{array}{l}\text { March } \\
2014\end{array}$ & $2 \mathrm{mg}$ & Once weekly & $\begin{array}{l}\text { Single-use pen } \\
(2 \mathrm{mg} \text {, requires } \\
\text { reconstitution) }\end{array}$ & $\begin{array}{l}\text { Refrigerate; or room } \\
\text { temperature for } \\
28 \text { days; room } \\
\text { temperature } 15 \text { minutes } \\
\text { before reconstitution }\end{array}$ & $\begin{array}{l}\mathrm{CrCl} 30-50 \mathrm{~mL} / \\
\mathrm{min}: \text { use caution } \\
\mathrm{CrCl}<30 \mathrm{~mL} / \mathrm{min}: \\
\text { not recommended }\end{array}$ & $\$ 610.22$ \\
\hline $\begin{array}{l}\text { Albiglutide } \\
\left(\text { Tanzeum }^{\circledR}\right)\end{array}$ & $\begin{array}{l}\text { April } \\
2014\end{array}$ & $\begin{array}{l}30 \mathrm{mg} \text {, can } \\
\text { increase to } 50 \mathrm{mg}\end{array}$ & Once weekly & $\begin{array}{l}\text { Single-use pen } \\
(30 \mathrm{mg}, 50 \mathrm{mg} \text {, } \\
\text { requires } \\
\text { reconstitution) }\end{array}$ & $\begin{array}{l}\text { Refrigerate; or room } \\
\text { temperature for } \\
28 \text { days; room } \\
\text { temperature } 15 \text { minutes } \\
\text { before reconstitution }\end{array}$ & None & $\$ 426.36$ \\
\hline $\begin{array}{l}\text { Dulaglutide } \\
\left(\text { Trulicity }^{\circledR}\right)\end{array}$ & $\begin{array}{l}\text { September } \\
2014\end{array}$ & $\begin{array}{l}0.75 \mathrm{mg} \text {, can } \\
\text { increase to } 1.5 \mathrm{mg}\end{array}$ & Once weekly & $\begin{array}{l}\text { Single-use pen } \\
(0.75 \mathrm{mg}, 1.5 \mathrm{mg})\end{array}$ & $\begin{array}{l}\text { Refrigerate; or room } \\
\text { temperature for } 14 \text { days }\end{array}$ & None & $\$ 638.16$ \\
\hline
\end{tabular}

Note: *Cost for maximum recommended dose.

Abbreviations: AWP, average wholesale price; $\mathrm{CrCl}$, creatinine clearance; FDA, US Food and Drug Administration; SC, subcutaneous.

been covalently linked by the constant fragment of human immunoglobulin class 4 . This modification leads to less renal clearance because of the larger size of the molecule. Both of these changes increase the duration of action of dulaglutide, allowing for once-weekly administration. ${ }^{28}$

\section{Pharmacokinetics}

The pharmacokinetics of dulaglutide do not appear to differ in patients with and without diabetes, nor do they differ based on the site of administration. ${ }^{22}$ Steady-state concentrations of once-weekly subcutaneous dulaglutide will occur within 2-4 weeks. The mean peak plasma concentration at a steady state is $114 \mathrm{ng} / \mathrm{mL}$, which will occur in a time to maximum concentration of 24-72 hours (median 48 hours). ${ }^{22,27}$ The total systemic exposure (area under the curve) is $14,000 \mathrm{ng} \cdot \mathrm{h} / \mathrm{mL}$. After a single subcutaneous dose of dulaglutide, bioavailability for the $0.75 \mathrm{mg}$ dose was $65 \%$ and for the $1.5 \mathrm{mg}$ dose was $47 \%$. Volume of distribution for the $0.75 \mathrm{mg}$ dose was approximately $19.2 \mathrm{~L}$ and was $17.4 \mathrm{~L}$ for the $1.5 \mathrm{mg}$ dose of dulaglutide. Dulaglutide is catabolized into amino acids by general protein breakdown, and it has an elimination half-life of 5 days. ${ }^{22,28}$ Although patients with renal dysfunction experience an increase in systemic exposure to dulaglutide, and patients with hepatic dysfunction experience a decrease in systemic exposure to dulaglutide, no dosing adjustments are recommended for patients with renal or hepatic dysfunction.
No dosing adjustments are needed for other factors, such as age, sex, race, or weight. As dulaglutide delays gastric emptying, there is the potential for drug interactions with respect to the absorption of orally administered medications; however, no clinically relevant drug interactions have been identified in clinical studies. ${ }^{22}$

\section{Efficacy}

In general, early dulaglutide studies demonstrated the efficacy of dulaglutide was dose-dependent, with increasing doses resulting in greater efficacy. One Phase I double-blind, placebo-controlled, crossover study examined escalating doses of dulaglutide $0.1,0.3,1,3,6$, and $12 \mathrm{mg} .{ }^{27}$ Reductions in blood glucose were found to be significantly better than placebo when the dose of dulaglutide was $1 \mathrm{mg}$ or greater.

In another double-blind, placebo-controlled parallel-group study, patients received once-weekly doses of $0.05,0.3,1,3$, 5 , or $8 \mathrm{mg}$ of subcutaneous dulaglutide. ${ }^{28}$ Significant reductions in fasting blood glucose were seen for the $0.05,1,3$, 5 , and $8 \mathrm{mg}$ doses, and significant reductions compared to placebo were seen in 2 hour postmeal glucose levels for all doses of $1 \mathrm{mg}$ or more.

The efficacy of dulaglutide was examined in overweight and obese patients by randomizing patients to either 16 weeks of placebo, 16 weeks of dulaglutide $1 \mathrm{mg}$, 4 weeks of dulaglutide $0.5 \mathrm{mg}$ followed by 12 weeks of dulaglutide 
$1 \mathrm{mg}$, or 4 weeks of dulaglutide $1 \mathrm{mg}$ followed by 12 weeks of dulaglutide $2 \mathrm{mg} .{ }^{29}$ Each active comparator group showed a significant reduction in A1c, fasting blood glucose, and postmeal glucose compared to placebo.

In a 12 week, double-blind, placebo-controlled study, patients received either placebo or dulaglutide $0.1,0.5,1$, or $1.5 \mathrm{mg}$ subcutaneously weekly. ${ }^{30}$ Reductions in A1c, fasting blood glucose, and postmeal blood glucose occurred in a dose-dependent manner. A1c reduction and fasting blood glucose reduction were significantly more compared to placebo for all active comparator groups except dulaglutide $0.1 \mathrm{mg}$ weekly.

A randomized, double-blind, placebo-controlled, parallelgroup study compared placebo and dulaglutide $0.25,0.5$, or $0.75 \mathrm{mg}$ subcutaneously weekly. ${ }^{31}$ Changes in A1c, fasting blood glucose, and postmeal blood glucose were dosedependent, and were significantly greater than placebo for all doses. The results of these early studies resulted in the six Phase III AWARD clinical studies, which focused on dulaglutide $0.75 \mathrm{mg}$ weekly and $1.5 \mathrm{mg}$ weekly. These studies ultimately led to the approval of dulaglutide by the US Food and Drug Administration (FDA).

The AWARD studies were randomized controlled studies that looked at weekly dulaglutide in more than 5,000 patients. Patients enrolled in these studies were prescribed a variety of background therapies. Patients in the AWARD-3 study were treatment-naïve at baseline. ${ }^{32}$ In the AWARD-5 and AWARD-6 studies, patients were receiving metformin alone. ${ }^{33,34}$ In the remaining AWARD studies, patients were taking metformin in combination with pioglitazone, ${ }^{35}$ glimepiride, ${ }^{36}$ or insulin lispro. ${ }^{37}$ Comparators of dulaglutide include placebo, ${ }^{35}$ insulin glargine, ${ }^{36,37}$ metformin, ${ }^{35}$ sitagliptin, ${ }^{33}$ and two other GLP-1 RAs: exenatide ${ }^{35}$ and liraglutide. ${ }^{34}$ A summary of the efficacy of dulaglutide as demonstrated in the AWARD studies can be found in Table 2.

The AWARD-1 study was a randomized study that compared dulaglutide $1.5 \mathrm{mg}$ and $0.75 \mathrm{mg}$ weekly to both exenatide $10 \mu \mathrm{g}$ twice daily and placebo. ${ }^{35}$ This study was designed to test for superiority of dulaglutide compared to placebo and noninferiority of dulaglutide compared to exenatide. Patients enrolled were uncontrolled, with a baseline A1c of 8.1\%, and on metformin 1,500-3,000 mg daily and pioglitazone $30-45 \mathrm{mg}$ daily. Throughout the 26 -week study period, both doses of dulaglutide led to greater reductions in A1c compared to placebo $(-1.51 \%,-1.30 \%,-0.46 \%$, respectively; $P<0.001$ for both comparisons). Over 26 weeks, patients taking dulaglutide $1.5 \mathrm{mg}$ and dulaglutide 0.75 $\mathrm{mg}$ also experienced a greater reduction in A1c compared to exenatide $(-1.51 \%,-1.30 \%,-0.99 \%$, respectively; $P<0.001$ for both comparisons). Patients assigned to both dulaglutide groups had significantly more A1c reduction over exenatide from baseline to 52 weeks as well $(-1.36 \%$, $-1.07 \%,-0.80 \%$, respectively; $P<0.001$ for both comparisons). Statistically more patients in both the dulaglutide $1.5 \mathrm{mg}$ and $0.75 \mathrm{mg}$ groups achieved an A1c less than $7 \%$ than in the exenatide and placebo groups $(78 \%, 66 \%, 52 \%$, $43 \%$, respectively; $P<0.001$ for both comparisons). Greater weight reduction was seen for patients in the dulaglutide $1.5 \mathrm{mg}$ and $0.75 \mathrm{mg}$ groups compared to placebo $(-1.30$, 0.20 , and $1.24 \mathrm{~kg}$, respectively; $P<0.001$ and $P<0.010$, respectively). While weight reduction was similar between patients in the dulaglutide $1.5 \mathrm{mg}$ group and exenatide group $(-1.30 \mathrm{~kg}$ vs $-1.07 \mathrm{~kg}$, not significant [NS]), patients in the dulaglutide $0.75 \mathrm{mg}$ group experienced less weight loss when compared to patients taking exenatide $(0.20 \mathrm{~kg}$ vs $-1.07 \mathrm{~kg}$, $P<0.001)$.

The AWARD-2 study was a randomized, open-label, noninferiority study that compared dulaglutide $1.5 \mathrm{mg}$ and $0.75 \mathrm{mg}$ to insulin glargine dosed to achieve fasting blood glucose levels $<100 \mathrm{mg} / \mathrm{dL} .{ }^{36}$ Patients included in this study were uncontrolled on metformin dosed at or above $1,500 \mathrm{mg}$ daily and glimepiride dosed at least $4 \mathrm{mg}$ daily. A lead-in period of 10-12 weeks allowed for discontinuation of other oral diabetes medications and doses of metformin and glimepiride to be titrated to the maximum tolerated doses. Baseline A1c was $8.1 \%$. Over 52 weeks, dulaglutide $1.5 \mathrm{mg}$ led to superior A1c reduction compared to insulin glargine $(-1.08 \%$ vs $0.63 \%, P<0.001)$. Dulaglutide $0.75 \mathrm{mg}$ was noninferior to insulin glargine for A1c lowering $(-0.76 \%$ vs $\left.-0.63 \% ; P_{\text {noninferiority }}<0.001\right)$. At 78 weeks, greater A1c reduction persisted, with patients in the dulaglutide $1.5 \mathrm{mg}$ group experiencing superior A $1 \mathrm{c}$ reduction compared to insulin glargine. Dulaglutide $0.75 \mathrm{mg}$ remained noninferior to insulin glargine at 78 weeks. After 52 weeks of treatment, significantly more patients achieved an A1c less than 7\% in the dulaglutide $1.5 \mathrm{mg}$ group compared to the insulin glargine group (53\% vs $31 \%, P<0.001)$. There was no difference between dulaglutide $0.75 \mathrm{mg}$ and insulin glargine in the percentage of patients achieving an A1c less than 7\%. Patients in both the dulaglutide $1.5 \mathrm{mg}$ and $0.75 \mathrm{mg}$ groups experienced weight loss, whereas patients in the insulin glargine group experienced weight gain $(-1.87 \mathrm{~kg},-1.33 \mathrm{~kg}$, and $1.44 \mathrm{~kg}$; $P<0.001$ for both comparisons).

The AWARD-3 study was a randomized, double-blind, noninferiority study that compared dulaglutide 0.75 and $1.5 \mathrm{mg}$ to metformin $1,500-2,000 \mathrm{mg}$ daily. ${ }^{32}$ Patients were 


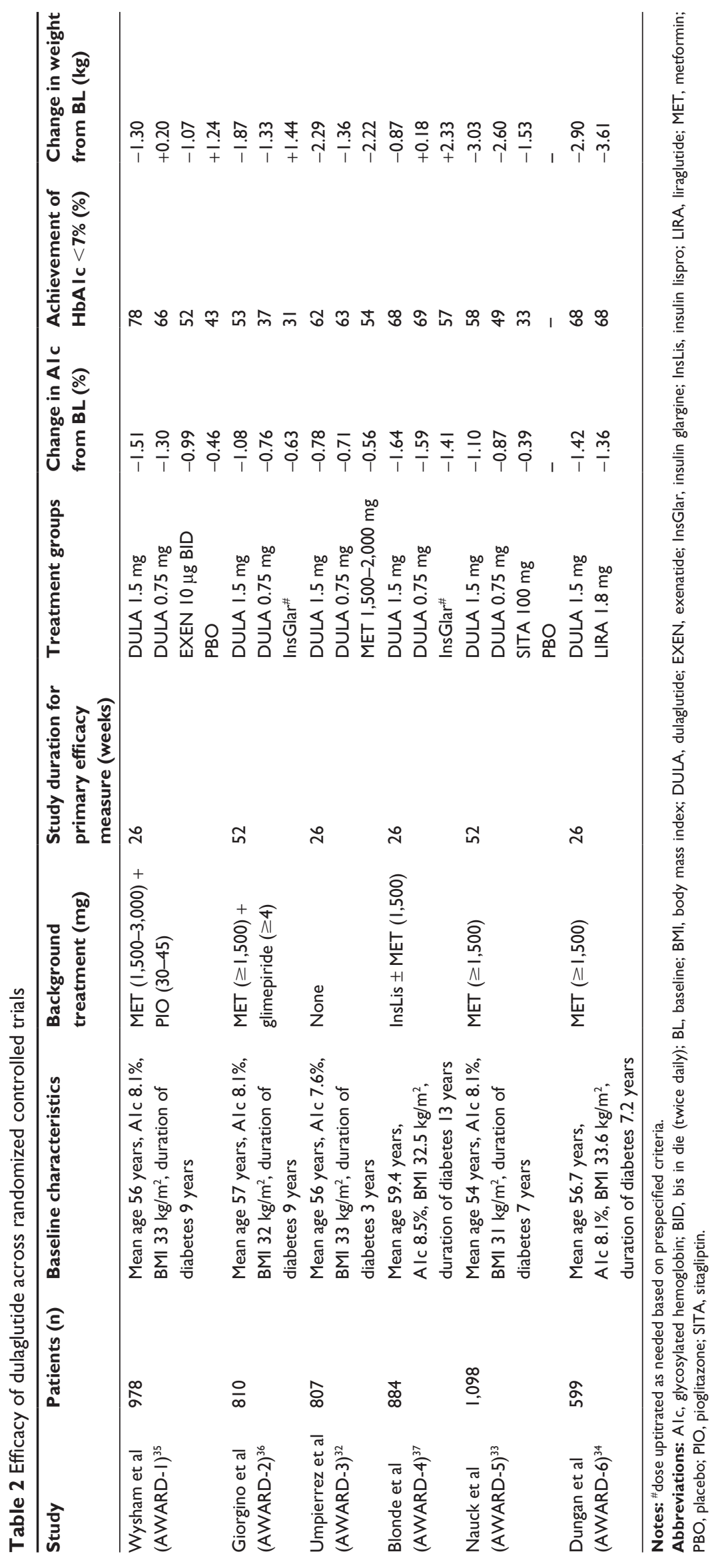


newly diagnosed with T2D and above goal A1c when treated with lifestyle modifications or one oral diabetes medication dosed at less than or equal to $50 \%$ of the maximum dose. Mean baseline A1c was 7.6\%. A 2-week washout period was included, during which all oral diabetes agents were stopped. Over 26 weeks, when compared to metformin, both doses of dulaglutide led to greater reductions in A1c, with the 1.5 $\mathrm{mg}$ dose of dulaglutide resulting in an A1c reduction of $0.78 \%$, the $0.75 \mathrm{mg}$ dose of dulaglutide resulting in an A1c reduction of $0.71 \%$, and metformin resulting in an A1c reduction of $0.56 \%(P=0.002$ for dulaglutide $1.5 \mathrm{mg}$ compared to metformin and $P=0.02$ for dulaglutide $0.75 \mathrm{mg}$ compared to metformin). At 52 weeks, dulaglutide $1.5 \mathrm{mg}$ remained significantly better than metformin with respect to A1c change $(-0.70 \%$ vs $-0.51 \%, P<0.02)$. However, at 52 weeks, there was no difference between dulaglutide 0.75 and metformin in A1c reduction $(-0.55 \%$ vs $-0.51 \%$, NS). After 26 weeks of treatment, significantly more patients on dulaglutide $1.5 \mathrm{mg}$ and $0.75 \mathrm{mg}$ achieved an A1c less than $7 \%$ compared to metformin $(62 \%, 63 \%, 54 \%$, respectively; $P=0.02$ for both comparisons). Throughout the 52-week study period, metformin and dulaglutide $1.5 \mathrm{mg}$ weekly led to similar weight loss $(-2.29$ vs $-2.22 \mathrm{~kg}$, NS). However, dulaglutide $0.75 \mathrm{mg}$ weekly led to less weight loss compared to metformin. ( $-1.36 \mathrm{vs}-2.22 \mathrm{~kg}, P=0.003)$.

The AWARD-4 study was a randomized, open-label, noninferiority study that compared dulaglutide $1.5 \mathrm{mg}$ and $0.75 \mathrm{mg}$ with insulin glargine using a treat-to-target algorithm. ${ }^{37}$ Patients were above goal A1c on insulin lispro with or without metformin 1,500 mg daily. Average baseline A1c was $8.5 \%$. Over 26 weeks, patients in the dulaglutide $1.5 \mathrm{mg}$ group achieved a greater reduction in A1c compared to insulin glargine $(-1.64 \%$ vs $-1.41 \%, P=0.005)$. Patients in the dulaglutide $0.75 \mathrm{mg}$ group also experienced a greater reduction in A1c compared to insulin glargine $(-1.59 \%$ vs $-1.41 \%, P=0.015)$. A $1 \mathrm{c}$ reduction for patients in both dulaglutide groups remained significantly greater than for those in the glargine group after 52 weeks. More patients in both the dulaglutide $1.5 \mathrm{mg}$ and $0.75 \mathrm{mg}$ groups achieved an A1c less than 7\% compared to patients in the insulin glargine group after 26 weeks of therapy $(68 \%, 69 \%, 57 \%$, respectively; $P=0.14,0.010$, respectively). Average weight loss in the dulaglutide $1.5 \mathrm{mg}$ group was greater than weight loss in patients in the insulin glargine group $(-0.87 \mathrm{~kg}$ vs $2.33 \mathrm{~kg}$, $P<0.0001$ ). Weight gain occurred in both the dulaglutide 0.75 $\mathrm{mg}$ and insulin glargine groups; however, average weight gain in the dulaglutide $0.75 \mathrm{mg}$ weekly was less than weight gain in the insulin glargine group ( 0.18 vs $2.33 \mathrm{~kg}, P<0.0001)$.
The AWARD-5 study was a randomized, double-blind study comparing dulaglutide $1.5 \mathrm{mg}$ and $0.75 \mathrm{mg}$ to sitagliptin $100 \mathrm{mg}$ daily and placebo. ${ }^{33}$ This study was designed to test for superiority of dulaglutide compared to placebo and noninferiority of dulaglutide compared to sitagliptin. Patients enrolled had a baseline A1c of $8.1 \%$ on metformin at or above $1,500 \mathrm{mg}$ daily. At 26 weeks, dulaglutide $1.5 \mathrm{mg}$ and $0.75 \mathrm{mg}$ led to a greater reduction in A1c compared to placebo $(-1.22 \%,-1.01 \%,-0.61 \%$, respectively; $P<0.001$ for both comparisons). After 52 weeks, patients in the dulaglutide $1.5 \mathrm{mg}$ group experienced a greater reduction in $\mathrm{A} 1 \mathrm{c}$ compared to sitagliptin $(-1.10 \%$ vs $-0.39 \% ; P<0.001)$. Patients in the dulaglutide $0.75 \mathrm{mg}$ group also experienced a greater reduction in A1c compared to the sitagliptin group $(-0.87 \%$ vs $-0.39 \%, P<0.001)$. Superior A1c reduction with both doses of dulaglutide persisted over the 104-week duration of the study $(-0.99 \%,-0.71 \%,-0.32 \% ; P<0.001$ for both comparisons). ${ }^{38}$ Statistically more patients achieved an A1c of less than 7\% in both dulaglutide groups compared to sitagliptin after 52 weeks and 104 weeks of treatment (52 weeks, 58\%, 49\%, 33\%, $P<0.001$ for both comparisons; 104 weeks, $54 \%, 45 \%, 31 \%, P<0.001$ for both comparisons). ${ }^{33,38}$ More weight loss occurred in both dulaglutide groups than in the sitagliptin group $(-3.03,-2.60,-1.53 \mathrm{~kg}$; $P<0.001$ for both comparisons).$^{33}$

The AWARD-6 study was a randomized, open-label, noninferiority study that compared dulaglutide $1.5 \mathrm{mg}$ weekly to the GLP-1 RA liraglutide $1.8 \mathrm{mg}$ daily. ${ }^{34}$ Patients enrolled were taking metformin dosed at or above $1,500 \mathrm{mg}$ daily. Baseline A1c was $8.1 \%$. After 26 weeks of therapy, patients in the dulaglutide group achieved A1c reduction that was noninferior to liraglutide $(-1.42 \%$ vs $-1.36 \%$, $\left.P_{\text {noninferiority }}<0.0001\right)$. A1c reduction for dulaglutide was not superior to that of liraglutide. There was no difference between groups in the percentage of patients achieving an A1c less than 7\%. Treatment with dulaglutide resulted in significantly less weight loss when compared to treatment with liraglutide $(-2.9 \mathrm{vs}-3.6 \mathrm{~kg}, P=0.011)$.

\section{Safety and tolerability}

In dose-finding studies of dulaglutide, the most commonly reported adverse effects were dose-related GI adverse effects. ${ }^{27-29}$ Patients also reported injection-site reactions, headaches, and nasopharyngitis. ${ }^{27,29}$ Dose-related increases in heart rate were also seen. ${ }^{27-29}$

In the six AWARD studies, overall incidence of adverse events was similar for dulaglutide compared to exenatide, ${ }^{35}$ metformin, ${ }^{32}$ sitagliptin, ${ }^{33}$ and liraglutide. ${ }^{34}$ In the AWARD-2 
Table 3 Safety of dulaglutide across randomized controlled trials

\begin{tabular}{|c|c|c|c|c|c|c|c|}
\hline Study & Treatment group & $\begin{array}{l}\text { Discontinuation } \\
\text { due to AEs (\%) }\end{array}$ & $\begin{array}{l}\text { Overall } \\
\text { GI AEs (\%) }\end{array}$ & Nausea (\%) & Vomiting (\%) & Diarrhea (\%) & $\begin{array}{l}\text { Total } \\
\text { hypoglycemia (\%) }\end{array}$ \\
\hline Wysham et al & DULA I.5 mg & 3 & 47 & 28 & 17 & 11 & 10.4 \\
\hline \multirow[t]{3}{*}{$(\text { AWARD-I })^{35}$} & DULA $0.75 \mathrm{mg}$ & I & 30 & 16 & 6 & 8 & 10.7 \\
\hline & EXEN $10 \mu g$ BID & 3 & 42 & 26 & 11 & 6 & 15.9 \\
\hline & $\mathrm{PBO}$ & 2 & 18 & 6 & 1 & 6 & 3.5 \\
\hline Giorgino et al & DULA 1.5 mg & 3.3 & NR & 15.4 & 6.6 & 10.6 & 55.3 \\
\hline \multirow[t]{2}{*}{$(\text { AWARD-2) })^{36}$} & DULA $0.75 \mathrm{mg}$ & 2.9 & & 7.7 & 3.7 & 9.2 & 54.4 \\
\hline & InsGlar & 1.9 & & 1.5 & 1.1 & 5.7 & 69.1 \\
\hline Umpierrez et al & DULA 1.5 mg & 4.8 & NR & 19 & 8.6 & 10 & 12.3 \\
\hline \multirow[t]{2}{*}{$(\text { AWARD-3) })^{32}$} & DULA $0.75 \mathrm{mg}$ & 2.2 & & 10.7 & 5.9 & 5.2 & II.I \\
\hline & MET I,500-2,000 mg & 3.7 & & 14.6 & 4.1 & 13.8 & 12.7 \\
\hline Blonde et al & DULA $1.5 \mathrm{mg}$ & 7 & NR & 25.8 & 12.2 & 16.6 & 86.6 \\
\hline \multirow[t]{2}{*}{$(\text { AWARD-4) })^{37}$} & DULA $0.75 \mathrm{mg}$ & 5 & & 17.7 & 10.6 & 15.7 & 90.1 \\
\hline & InsGlar & 4 & & 3.4 & 1.7 & 6.1 & 90.2 \\
\hline Nauck et al & DULA $1.5 \mathrm{mg}$ & 10.9 & 41 & 17 & 13 & 15 & 10.2 \\
\hline \multirow[t]{2}{*}{$(\text { AWARD }-5)^{33}$} & DULA $0.75 \mathrm{mg}$ & 7.6 & 37 & 14 & 8 & 10 & 5.3 \\
\hline & SITA $100 \mathrm{mg}$ & 9.5 & 23 & 5 & 2 & 3 & 4.8 \\
\hline Dungan et al & DULA 1.5 mg & 6 & 36 & 20 & 7 & 12 & 9 \\
\hline$(\text { AWARD-6) })^{34}$ & LIRA I.8 mg & 6 & 36 & 18 & 8 & 12 & 6 \\
\hline
\end{tabular}

Abbreviations: AE, adverse effects; BID, bis in die (twice daily); DULA, dulaglutide; EXEN, exenatide; GI, gastrointestinal; InsGlar, insulin glargine; LIRA, liraglutide; NR, not reported; PBO, placebo; SITA, sitagliptin; MET, metformin.

study, rates of adverse events were similar between dulaglutide and insulin glargine. ${ }^{36}$ However, in the AWARD-4 study, serious adverse events occurred more frequently with insulin glargine than dulaglutide, and overall adverse events occurred more frequently with dulaglutide than insulin glargine. ${ }^{37}$ Discontinuation rates were similar for dulaglutide compared to exenatide, ${ }^{35}$ insulin glargine, ${ }^{36}$ metformin, ${ }^{32}$ sitagliptin, ${ }^{33}$ and liraglutide. ${ }^{34}$ An overview of adverse events from the AWARD studies can be found in Table 3 .

\section{Gastrointestinal adverse events}

GI adverse events make up the majority of adverse events related to dulaglutide use, which is consistent with other GLP-1 RAs. In the AWARD studies, GI side effects were mild to moderate in severity ${ }^{32,34-37}$ and resolved with time. ${ }^{33-37}$ Compared to placebo, dulaglutide dosed at both $1.5 \mathrm{mg}$ and $0.75 \mathrm{mg}$ led to more GI events in the AWARD-1 study $(47 \%, 30 \%, 18 \% ; P<0.001, P<0.05$, respectively, vs placebo) ${ }^{35}$ Similar results were seen in the AWARD-5 study, with dulaglutide $1.5 \mathrm{mg}$ and $0.75 \mathrm{mg}$ resulting in more GI side effects compared to placebo after 26 weeks ( $38 \%, 32 \%, 23 \%$; $P<0.001, P<0.05$, respectively). Both dulaglutide $1.5 \mathrm{mg}$ and $0.75 \mathrm{mg}$ led to more GI side effects than sitagliptin ( $41 \%, 37 \%$, $23 \% ; P<0.001$ for both comparisons). ${ }^{33}$ When compared to insulin glargine, dulaglutide resulted in more GI side effects. In the AWARD-2 study, nausea was more common in patients taking dulaglutide 1.5 and $0.75 \mathrm{mg}$ compared to insulin glargine (15.4\%, 7.7\%, $1.5 \%$, respectively; $P<0.001$ for both comparisons).$^{36}$ In the AWARD-4 study, nausea, vomiting, and diarrhea all occurred significantly more with both dulaglutide $1.5 \mathrm{mg}$ and $0.75 \mathrm{mg}$ versus insulin glargine (nausea, $26 \%, 18 \%$, $3 \%, P<0.0001$ for both comparisons; vomiting, $12 \%, 11 \%$, $2 \%, P<0.0001$ for both comparisons; diarrhea, $17 \%, 16 \%$, $6 \%, P<0.001, P=0.0002$, respectively, vs insulin glargine). ${ }^{37}$ Overall, GI adverse events were similar when comparing dulaglutide to both liraglutide ${ }^{34}$ and metformin..$^{35}$ Although GI adverse events were similar with dulaglutide $1.5 \mathrm{mg}$ and exenatide ( $47 \%$ vs $42 \%$, NS), dulaglutide $0.75 \mathrm{mg}$ led to fewer GI events compared to exenatide ( $30 \%$ vs $42 \%, P<0.05$ ). ${ }^{35}$

\section{Pancreatitis}

Although the data are conflicting, increased risk of pancreatitis with GLP-1 inhibitors compared to other nonincretin therapies has been demonstrated. ${ }^{39}$ Pancreatic enzymes increased in patients taking dulaglutide in all of the AWARD studies. ${ }^{32-37}$ Only in the AWARD-2 study did patients randomized to dulaglutide develop pancreatitis. ${ }^{36}$ Two of these cases were acute, occurring 1 day and 302 days after the initiation of dulaglutide. The remaining case of chronic pancreatitis occurred after 107 days of dulaglutide. Two patients were taking dulaglutide $1.5 \mathrm{mg}$, and one patient was taking dulaglutide $0.75 \mathrm{mg}$.

In total, 12 patients receiving dulaglutide in Phase II and III studies developed an adverse event due to pancreatitis. ${ }^{22}$ Comparatively, three patients taking nonincretin agents 
developed an adverse event due to pancreatitis. Pancreatitis was confirmed in five patients prescribed dulaglutide and one patient taking a nonincretin agent. Patients prescribed dulaglutide should be monitored for signs and symptoms of pancreatitis, and dulaglutide should be discontinued if pancreatitis occurs. ${ }^{22}$ As a caution, the FDA has mandated pancreatitis in the Risk Evaluation and Mitigation Strategy (REMS) program for dulaglutide. ${ }^{22,40}$

\section{Hypoglycemia}

The incidence of hypoglycemia was low in the AWARD studies, and rates of hypoglycemia with dulaglutide were higher in the studies that included background treatment associated with hypoglycemia. When dulaglutide and exenatide were compared, patients taking dulaglutide experienced less hypoglycemia ( $10.4 \%$ vs $15.9 \%, P=0.007) .{ }^{35}$ Dulaglutide 1.5 and $0.75 \mathrm{mg}$ led to less hypoglycemia than insulin glargine (55.3\%, 54.4\%, 69.1\%, respectively; $P=0.001$ for dulaglutide $1.5 \mathrm{mg}$ and $P<0.001$ for dulaglutide $0.75 \mathrm{mg}) .{ }^{36}$ Similarly, the AWARD-4 study found lower rates of hypoglycemia with dulaglutide $1.5 \mathrm{mg}$ than with insulin glargine $(31.0,39.9$ events/patient/year, respectively; $P<0.036) .{ }^{37}$ There was not a significant difference in rates of hypoglycemia when comparing dulaglutide $1.5 \mathrm{mg}$ and $0.75 \mathrm{mg}$ to metformin in the AWARD-3 study $(12.3 \%, 11.1 \%, 12.7 \%$, respectively; NS).$^{32}$ Incidence of hypoglycemic events was $10.2 \%$ for dulaglutide $1.5 \mathrm{mg}, 5.3 \%$ for dulaglutide $0.75 \mathrm{mg}$, and $4.8 \%$ for sitagliptin ( $P$-value not reported) in the AWARD-5 study, ${ }^{33}$ and the incidence of hypoglycemic events was $9 \%$ for dulaglutide and $6 \%$ for liraglutide ( $P$-value not reported) in the AWARD-6 study. ${ }^{34}$

\section{Cardiovascular effects}

In general, GLP-1 RAs led to clinically significant reductions in blood pressure, typically in individuals with elevated baseline blood pressure. ${ }^{41}$ They have led to persistent increases in heart rate. ${ }^{41}$ Using ambulatory blood pressure monitoring, one 26-week, randomized, double-blind, placebo-controlled study compared dulaglutide to placebo for changes in blood pressure and heart rate. ${ }^{42}$ Compared to placebo, dulaglutide $1.5 \mathrm{mg}$ significantly reduced blood pressure and significantly increased heart rate. When compared to metformin, liraglutide, exenatide, sitagliptin, and insulin glargine, dulaglutide led to no significant differences in blood pressure. ${ }^{32-37}$ Dulaglutide did not lead to any significant differences in heart rate when compared to metformin, liraglutide, or exenatide. ${ }^{32,34,35}$ However, at week 52 , dulaglutide $1.5 \mathrm{mg}$ and $0.75 \mathrm{mg}$ did lead to a significant increase in heart rate compared to sitagliptin (2.4, 2.1, $-0.3 \mathrm{bpm}$, respectively; $P<0.001$ for both comparisons). ${ }^{33}$ In the AWARD-2 study, the mean heart rate increased in patients treated with dulaglutide, but decreased in patients treated with insulin glargine ( $P$-value not reported). ${ }^{36,37}$ Similarly, in the AWARD-4 study, dulaglutide $1.5 \mathrm{mg}$ led to significant increases in heart rate compared to insulin glargine (2.38 vs 0.93 bpm, $P=0.047$ ). ${ }^{37}$

Thyroid C-cell tumors have been associated with dulaglutide in male and female rats; the incidence is dose- and duration-dependent. Although dulaglutide has not been associated with thyroid C-cell tumors in humans, due to the incidence in rats, it is contraindicated in human patients with thyroid C-cell tumors. As with other GLP-1 RAs, dulaglutide carries a black-box warning of potential thyroid C-cell tumors for dulaglutide, and the REMS program for dulaglutide also cautions about this potential. ${ }^{40}$

\section{Patient-focused perspectives}

While clinical studies have demonstrated the efficacy and safety of dulaglutide, the overall success of therapy will depend on patient adherence to the medication. This may be of greater concern for an injectable medication, such as dulaglutide, as negative treatment outcomes have been associated with a fear of injections. ${ }^{43}$ It is imperative to look at patient-reported outcomes because they reveal patient perspectives, measure treatment satisfaction, and may be indicative of medication adherence. ${ }^{44}$

Patient-reported outcomes have improved as manufacturers have worked to improve injection systems. ${ }^{45}$ The dulaglutide-injection system contains $0.75 \mathrm{mg} / 0.5 \mathrm{~mL}$ or $1.5 \mathrm{mg} / 0.5 \mathrm{~mL}$ of dulaglutide solution in a single-dose pen. ${ }^{46}$ The disposable, prefilled pen device is supplied with a needle already attached and does not require reconstitution. Although the patient must initiate the injection, the actual insertion and retraction of the needle are automated. To use the pen, patients must remove a base cap that exposes the needle. The patient must place the clear base firmly against the skin at the injection site. The pen must then be unlocked by turning the lock ring. The patient injects by pressing and holding the injection button for 5-10 seconds. The patient should hear a loud click when the injection button is pressed and a second loud click after 5-10 seconds, indicating that the needle is retracting. ${ }^{46}$

Use of the pen device was studied in a Phase IIIB openlabel study. Patients naïve to injections were included to determine if the dulaglutide pen device can be used safely and effectively. ${ }^{47}$ Patients were trained on how to inject placebo using the dulaglutide pen device and were provided 
with instructions for use. Ninety-nine percent of patients were able to successfully self-administer the final injection in the 4-week study. Even at baseline, 97\% of patients were able to administer placebo successfully via the dulaglutide pen device. Nearly all patients (99\%) reported the pen was "easy" or "very easy" to use. Most patients also found the pen device convenient to use and were confident in their ability to use the pen. Patients appreciated that the needle did not have to be touched or seen with the device. Fear of self-injecting significantly decreased over the 4-week study.

Four of the AWARD trials also measured overall treatment satisfaction with dulaglutide. The Diabetes Treatment Satisfaction Questionnaire (DTSQ) was administered in the AWARD-1 and AWARD-3 studies. ${ }^{48}$ The DTSQ status (DTSQs) version measures absolute treatment satisfaction, whereas the DTSQ change (DTSQc) version measures the change in treatment satisfaction from baseline. In the AWARD-1 study, statistically significant improvements were seen in DTSQs scores for both dulaglutide groups compared to baseline at 26 and 52 weeks. DTSQs scores were significantly better for dulaglutide than exenatide and placebo as well. Patients taking dulaglutide experienced a significant improvement in DTSQc scores at 52 weeks. Significant improvements in the DTSQs scores were seen for both dulaglutide and metformin in the AWARD-3 study, and improvements were similar for both groups. DTSQc scores improved for both dulaglutide and metformin at 52 weeks.

Patient-reported outcomes were measured in the AWARD-2 study through the use of the following measures: ability to perform activities of daily living, the impact of weight on self-perception, and the low blood sugar survey behavior and worry measures. ${ }^{49}$ Compared to insulin glargine, patient-reported outcomes were significantly improved with dulaglutide for all measures studied. The AWARD-6 study also examined patient-reported outcomes. ${ }^{34}$ Both liraglutide and dulaglutide led to significant improvements in the impact of weight on self-perception scores. The dulaglutide group had significant improvements from baseline in ability to perform physical activities of daily living and quality-of-life scores. These results indicate overall patient satisfaction with the dulaglutide-injection system, as well as dulaglutide itself.

\section{Conclusion}

With their demonstrated efficacy and long-term safety profile, GLP-1 RAs as a class are an appealing option for the treatment of T2D. In particular, the low rates of hypoglycemia and the weight loss associated with their use give them a distinct advantage over other agents. Disadvantages do exist, and include adverse GI side effects, cost, and the fact that they are injectable. As a GLP-1 RA, dulaglutide is dosed once weekly, and studies have demonstrated treatment satisfaction with both the injection system as well as the medication itself. Therefore, dulaglutide is a viable second-line option after metformin, with demonstrated superior efficacy to other second-line agents, including sitagliptin, insulin glargine, and the GLP-1 RA exenatide twice daily.

\section{Disclosure}

The authors report no conflicts of interest in this work.

\section{References}

1. International Diabetes Federation. IDF Diabtes Atlas. 6th ed. Brussels, Belgium: International Diabetes Federation; 2014. Available from: http:// www.idf.org/diabetesatlas/update-2014. Accessed August 8, 2015.

2. Centers for Disease Control and Prevention. National Diabetes Statistics Report: Estimates of Diabetes and Its Burden in the United States, 2014. Atlanta, GA: US Department of Health and Human Services; 2014. Available from: http://www.cdc.gov/diabetes/pubs/statsreport14/ national-diabetes-report-web.pdf. Accessed August 8, 2015.

3. Defronzo RA. Banting Lecture. From the triumvirate to the ominous octet: a new paradigm for the treatment of type 2 diabetes mellitus. Diabetes. 2009;58:773-795.

4. American Diabetes Association. Standards of medical care in diabetes 2015. Diabetes Care. 2015;38(Suppl 1):S1-S93.

5. Inzucchi SE, Bergenstal RM, Buse JB, et al. Management of hyperglycemia in type 2 diabetes: a patient-centered approach: position statement of the American Diabetes Association (ADA) and the European Association for the Study of Diabetes (EASD). Diabetes Care. 2012;35:1364-1379.

6. Inzucchi SE, Bergenstal RM, Buse JB, et al. Management of hyperglycemia in type 2 diabetes, 2015: a patient-centered approach: update to a position statement of the American Diabetes Association and the European Association for the Study of Diabetes. Diabetes Care. 2015;38: 140-149.

7. Garber AJ, Abrahamson MJ, Barzilay JI, et al. AACE/ACE comprehensive diabetes management algorithm 2015. Endocr Pract. 2015;21:438-447.

8. Handelsman Y, Bloomgarden ZT, Grunberger G, et al. American Association of Clinical Endocrinologists and American College of EndocrinologyClinical Practice Guidelines for Developing a Diabetes Mellitus Comprehensive Care Plan - 2015. Endocr Pract. 2015;21 (Suppl 1):1-87.

9. Holman RR, Paul SK, Bethel MA, Matthews DR, Neil HA. 10-Year follow-up of intensive glucose control in type 2 diabetes. NEngl J Med. 2008;359:1577-1589.

10. Cefalu WT, Buse JB, Del Prato S, et al. Beyond metformin: safety considerations in the decision-making process for selecting a second medication for type 2 diabetes management: reflections from a diabetes care editors' expert forum. Diabetes Care. 2014;37:2647-2659.

11. Stark Casagrande S, Fradkin JE, Saydah SH, Rust KF, Cowie CC. The prevalence of meeting A1C, blood pressure, and LDL goals among people with diabetes, 1988-2010. Diabetes Care. 2013;36:2271-2279.

12. Green JB, Bethel MA, Armstrong PW, et al. Effect of sitagliptin on cardiovascular outcomes in type 2 diabetes. N Engl J Med. 2015;373: 232-242.

13. Scirica BM, Bhatt DL, Braunwald E, et al. Saxagliptin and cardiovascular outcomes in patients with type 2 diabetes mellitus. $N$ Engl J Med. 2013;369:1317-1326.

14. White WB, Cannon CP, Heller SR, et al. Alogliptin after acute coronary syndrome in patients with type 2 diabetes. N Engl J Med. 2013;369: 1327-1335. 
15. Pfeffer M. The evaluation of lixisenatide in acute coronary syndromethe results of ELIXA. Poster presented at: American Diabetes Association 2015 Scientific Sessions; June 8, 2015; Boston, MA.

16. Eli Lilly and Company. The effect of dulaglutide on major cardiovascular events in patients with type 2 diabetes: researching cardiovascular events with a weekly incretin in diabetes (REWIND). Available from: http:// clinicaltrials.gov/show/NCT01394952. NLM identifier: NCT01394952. Accessed November 4, 2015.

17. Ou SM, Shih CJ, Chao PW, et al. Effects on clinical outcomes of adding dipeptidyl peptidase-4 inhibitors versus sulfonylureas to metformin therapy in patients with type 2 diabetes mellitus. Ann Intern Med. 2015;163:663-672.

18. Zinman B, Wanner C, Lachin JM, et al. Empagliflozin, cardiovascular outcomes, and mortality in type 2 diabetes. $N$ Engl J Med. Epub 2015 Sep 17.

19. Grandy S, Fox KM, Hardy E, Group SS. Association of weight loss and medication adherence among adults with type 2 diabetes mellitus: SHIELD (Study to Help Improve Early evaluation and management of risk factors Leading to Diabetes). Curr Ther Res Clin Exp. 2013;75: 77-82.

20. Turner LW, Nartey D, Stafford RS, Singh S, Alexander GC. Ambulatory treatment of type 2 diabetes in the US, 1997-2012. Diabetes Care. 2014;37:985-992.

21. Trujillo JM, Nuffer W. GLP-1 receptor agonists for type 2 diabetes mellitus: recent developments and emerging agents. Pharmacotherapy. 2014;34(11):1174-1186.

22. Trulicity ${ }^{\circledR}$ (dulaglutide) for injection [package insert]. Indianapolis: Eli Lily; 2015

23. Victoza ${ }^{\circledR}$ (liraglutide) for injection [package insert]. Bagsvaerd, Denmark: Novo Nordisk; 2015.

24. Tanzeum ${ }^{\circledR}$ (albiglutide) for injection [package insert]. Wilmington, DE: GlaxoSmithKline; 2015.

25. Byetta $^{\circledR}$ (exenatide) for injection [package insert]. Wilmington, DE: AstraZeneca Pharmaceuticals; 2015

26. Bydureon ${ }^{\circledR}$ (exenatide extended-release) for injectable suspension [package insert]. Wilmington, DE: AstraZeneca Pharmaceuticals; 2015.

27. Barrington P, Chien JY, Tibaldi F, Showalter HD, Schneck K, Ellis B. LY2189265, a long-acting glucagon-like peptide-1 analogue, showed a dose-dependent effect on insulin secretion in healthy subjects. Diabetes Obes Metab. 2011;13:434-438.

28. Barrington P, Chien JY, Showalter HD, et al. A 5-week study of the pharmacokinetics and pharmacodynamics of LY2189265, a novel, long-acting glucagon-like peptide-1 analogue, in patients with type 2 diabetes. Diabetes Obes Metab. 2011;13:426-433.

29. Umpierrez GE, Blevins T, Rosenstock J, Cheng C, Anderson JH, Bastyr EJ 3rd. The effects of LY2189265, a long-acting glucagon-like peptide-1 analogue, in a randomized, placebo-controlled, double-blind study of overweight/obese patients with type 2 diabetes: the EGO study. Diabetes Obes Metab. 2011;13:418-425.

30. Grunberger G, Chang A, Garcia Soria G, Botros FT, Bsharat R, Milicevic Z. Monotherapy with the once-weekly GLP-1 analogue dulaglutide for 12 weeks in patients with type 2 diabetes: dose-dependent effects on glycaemic control in a randomized, double-blind, placebo-controlled study. Diabet Med. 2012;29:1260-1267.

31. Terauchi Y, Satoi Y, Takeuchi M, Imaoka T. Monotherapy with the once weekly GLP-1 receptor agonist dulaglutide for 12 weeks in Japanese patients with type 2 diabetes: dose-dependent effects on glycaemic control in a randomised, double-blind, placebo-controlled study. Endocr J. 2014;61:949-959.

32. Umpierrez G, Tofé Povedano S, Pérez Manghi F, Shurzinske L, Pechtner V. Efficacy and safety of dulaglutide monotherapy versus metformin in type 2 diabetes in a randomized controlled trial (AWARD-3). Diabetes Care. 2014;37:2168-2176.
33. Nauck M, Weinstock RS, Umpierrez GE, Guerci B, Skrivanek Z, Milicevic Z. Efficacy and safety of dulaglutide versus sitagliptin after 52 weeks in type 2 diabetes in a randomized controlled trial (AWARD-5). Diabetes Care. 2014;37:2149-2158.

34. Dungan KM, Povedano ST, Forst T, et al. Once-weekly dulaglutide versus once-daily liraglutide in metformin-treated patients with type 2 diabetes (AWARD-6): a randomised, open-label, phase 3, noninferiority trial. Lancet. 2014;384:1349-1357.

35. Wysham C, Blevins T, Arakaki R, et al. Efficacy and safety of dulaglutide added onto pioglitazone and metformin versus exenatide in type 2 diabetes in a randomized controlled trial (AWARD-1). Diabetes Care. 2014;37:2159-2167.

36. Giorgino F, Benroubi M, Sun JH, Zimmermann AG, Pechtner V. Efficacy and safety of once-weekly dulaglutide versus insulin glargine in patients with type 2 diabetes on metformin and glimepiride (AWARD-2). Diabetes Care. Epub 2015 Jun 18.

37. Blonde L, Jendle J, Gross J, et al. Once-weekly dulaglutide versus bedtime insulin glargine, both in combination with prandial insulin lispro, in patients with type 2 diabetes (AWARD-4): a randomised, open-label, phase 3, non-inferiority study. Lancet. 2015;385:2057-2066.

38. Weinstock RS, Guerci B, Umpierrez G, Nauck MA, Skrivanek Z, Milicevic Z. Safety and efficacy of once-weekly dulaglutide versus sitagliptin after 2 years in metformin-treated patients with type 2 diabetes (AWARD-5): a randomized, phase III study. Diabetes Obes Metab. 2015;17:849-858.

39. Elashoff M, Matveyenko AV, Gier B, Elashoff R, Butler PC. Pancreatitis, pancreatic, and thyroid cancer with glucagon-like peptide-1-based therapies. Gastroenterology. 2011;141:150-156.

40. Eli Lilly. Trulicity REMS (risk evaluation and mitigation strategy). Available from: http://www.trulicityrems.com. Accessed August 10, 2015.

41. Gallwitz B. Extra-pancreatic effects of incretin-based therapies. Endocrine. 2014;47:360-371.

42. Ferdinand KC, White WB, Calhoun DA, et al. Effects of the once-weekly glucagon-like peptide-1 receptor agonist dulaglutide on ambulatory blood pressure and heart rate in patients with type 2 diabetes mellitus. Hypertension. 2014;64:731-737.

43. Fu AZ, Qiu Y, Radican L. Impact of fear of insulin or fear of injection on treatment outcomes of patients with diabetes. Curr Med Res Opin. 2009;25:1413-1420.

44. Barbosa CD, Balp MM, Kulich K, Germain N, Rofail D. A literature review to explore the link between treatment satisfaction and adherence, compliance, and persistence. Patient Prefer Adherence. $2012 ; 6: 39-48$

45. Ross SA. Breaking down patient and physician barriers to optimize glycemic control in type 2 diabetes. Am J Med. 2013;126:S38-S48.

46. Eli Lilly. Instructions for use: Trulicity (dulaglutide). Available from: http://pi.lilly.com/us/trulicity-highdose-ai-ifu.pdf. 2014. Accessed August 10, 2015.

47. Matfin G, Van Brunt K, Zimmermann AG, Threlkeld R, Ignaut DA. Safe and effective use of the once weekly dulaglutide single-dose pen in injection-naïve patients with type 2 diabetes. J Diabetes Sci Technol. 2015;9:1071-1079.

48. Reaney M, Yu M, Lakshmanan M, Pechtner V, van Brunt K. Treatment satisfaction in people with type 2 diabetes mellitus treated with once-weekly dulaglutide: data from the AWARD-1 and AWARD-3 clinical trials. Diabetes Obes Metab. 2015;17:896-903.

49. Giorgino F, Benroubi M, Sun J, et al. Efficacy and safety of onceweekly dulaglutide vs insulin glargine in combination with metformin and glimepiride in type 2 diabetes patients (AWARD-2). Diabetologia. 2014;57 (Suppl 1):A38.

50. Truven Health Analytics. Red Book: a comprehensive, consistent drug pricing resource. Available from: http://micromedex.com/redbook. Accessed November 13, 2015. 


\section{Publish your work in this journal}

Diabetes, Metabolic Syndrome and Obesity: Targets and Therapy is opinion and commentaries are all considered for publication. The an international, peer-reviewed open-access journal committed to the rapid publication of the latest laboratory and clinical findings in the fields of diabetes, metabolic syndrome and obesity research. Original research, review, case reports, hypothesis formation, expert manuscript management system is completely online and includes a very quick and fair peer-review system, which is all easy to use. Visit http://www.dovepress.com/testimonials.php to read real quotes from published authors.

Submit your manuscript here: http://www.dovepress.com/diabetes-metabolic-syndrome-and-obesity-targets-and-therapy-journal 